\title{
versants
}

\section{Pintura y Panegírico. Usos de la écfrasis en Manoel de Galhegos}

\author{
Jesús Ponce CÁrdenas ${ }^{\mathrm{I}}$ \\ Universidad Complutense de Madrid
}

\begin{abstract}
Se analiza la Silva topográfica al Buen Retiro de Manoel de Galhegos, consagrando especial atención a la presencia de la écfrasis en el poema y la función laudatoria que reviste.

Keywords: Pintura, panegírico, écfrasis, Manoel de Galhegos, Buen Retiro, Velázquez, Rubens.
\end{abstract}

El propósito de este breve ensayo es reflexionar acerca de los vínculos que mantuvieron durante el Siglo de Oro las prácticas literarias del elogio y la descripción lírica de pinturas. A partir del comentario de varios fragmentos de la Silva topográfica al Buen Retiro, composición barroca del escritor luso Manoel de Galhegos, trataremos de iluminar algunos haces de relación que afectan a la pictura y a la laudatio. Nuestra reflexión se articulará en torno a tres ejes principales. El primero de ellos gira en torno a los lazos entre poesía descriptiva y poder, con especial atención a los espacios afines del jardín (regio o nobiliario), el palacio y la galería. Seguidamente se indagará en cómo se desarrollaron desde el campo literario diversas estrategias de legitimación de la nueva residencia real del Buen Retiro, cuya edificación estuvo rodeada de polémica. Finalmente, se examinarán los varios matices que ofrece la transposición artística (referida a obras de Rubens, Snyders, Reni o Velázquez) en la Silva de un escritor portugués afincado en la corte de los Austrias menores.

\section{Poesía descriptiva y poder: jardín, palacio, galería}

En el amplio arco temporal que comprende los reinados de Felipe II (I556-I598), Felipe III (I598-I62I) y Felipe IV (I62I-I665), vio la luz en España un novedoso género de carácter descriptivo-laudatorio. Conforme a las prácticas de la imitatio, este tipo de escritura poética nacía bajo la inspiración del dechado estaciano de las Silvas, espoleada asimismo por modelos

I Este trabajo se inscribe en el Proyecto de Investigación «Las Artes del Elogio: Poesía, Retórica e Historia en los Panegíricos hispanos» (ARELPH / FFI2015-63554-P), financiado por el Ministerio de Economía y Competitividad, en el apartado del Programa Estatal de Fomento de la Investigación Científica y Técnica de Excelencia. 
de origen italiano. Como se ha apuntado en alguna reciente aportación, los ingenios españoles se inspiraron en un notable conjunto de composiciones neolatinas y vernáculas dedicadas a las villas aristocráticas y jardines monumentales diseminados por Liguria, el Véneto, Emilia Romania, Toscana, Campania o el Lacio².

Desde el punto de vista histórico-cultural, la nueva modalidad lírica emergía en las letras hispánicas como respuesta a la construcción de suntuosos espacios de recreo y recogimiento impulsada por las élites del reino, al tiempo que daba cuenta de una rica tipología edilicia. En efecto, aquellos versos sirvieron para exaltar un notable conjunto de residencias reales (Aranjuez, el Buen Retiro, Hirscholme), diversas mansiones de la más selecta aristocracia (la Abadía, la Tapada, la casa jardín del conde de Monterrey en el Paseo del Prado Viejo, la quinta del conde de Casarrubios), varias moradas de recreo de altos jerarcas de la Iglesia (el Cigarral de Buena Vista en Toledo, la Quinta de Santa Cruz en Oporto), algunos jardines monásticos (la Cartuja de Aula Dei en Zaragoza) y también residencias privadas de la baja nobleza urbana (el Carmen de los Mascarones en Granada).

Haciendo algo de memoria, los tres primeros hitos en la historia de esta modalidad poética se pueden datar en torno al último cuarto del siglo XVI (Orozco Díaz I947 y 20I0). El testimonio más temprano es el de la Égloga pastoril en que se describe el Bosque de Aranjuez, cuya autoría se la disputan el docto Gregorio Hernández de Velasco, insigne traductor de Virgilio, y Luis Gómez de Tapia, bajo cuyo nombre vio la luz en una edición de I582. No mucho después, en 1589, Lupercio Leonardo de Argensola daba a las prensas los Tercetos en que se describe Aranjuez, lugar favorito del soberano Felipe II y su hija, la infanta Isabel Clara Eugenia. De esa etapa inicial del elogio rimado de los jardines regios y nobiliarios podríamos considerar como la obra más destacada la Descripción de la Abadía, jardín del duque de Alba, extensa composición en octavas, redactada por Lope de Vega hacia la primavera de I592.

Rebasados los límites de aquella centuria, los poemas-jardines del Barroco reservaron, a menudo, un lugar de honor para la écfrasis de pinturas. Baste evocar aquí el significativo testimonio del granadino Pedro Soto de Rojas, autor del magistral Paraíso cerrado para muchos, jardín abierto para pocos, en una de cuyas mansiones incorporó un breve elenco de los cuadros que poseía (mansión VI, vv. 739-8I4). Ese sucinto fragmento lírico permite que nos asomemos hoy a la pequeña colección de un canónigo andaluz de mediados del siglo xvir: allí figuraban obras de artistas nacionales (un

2 Se puede ampliar la información sobre fuentes clásicas, neolatinas e italianas de este tipo de composiciones descriptivas en la reciente monografía de Ponce Cárdenas y Rivas Albaladejo (2018). Sobre el ámbito italiano en general, véase Caruso (1997). Para el entorno napolitano, remito a las magistrales aportaciones de Hernando Sánchez (I998 y 2013). 
lienzo de Alonso de Guevara, un bodegón de frutas de Blas de Ledesma, un cuadro de Jusepe de Ribera, una pintura de Bartolomé Alberto, otra de Pedro de Raxis) y de un maestro extranjero (Jacopo Bassano). Por otro lado, resulta notabilísimo el testimonio de la segunda Selva Dánica, compleja y extensa composición en la que el conde de Rebolledo pergeñaba la descripción del palacio campestre de Hirscholme, propiedad de la familia real de Dinamarca. El embajador español fue acogido en el mismo en I654 y, correspondiendo a tan generosa hospitalidad, al año siguiente daba cuenta en una suntuosa silva de los varios frescos de Karel Van Mander III así como de un interesante conjunto de cuadros de las colecciones reales danesas, con escenas de caza y una pequeña galería de retratos.

\section{La legitimación de una morada regia: cauces laudatorios en la Silva topográfica al Buen Retiro}

La figura de Manoel de Galhegos (I597-I665) forma parte de la nutrida pléyade de ingenios menores del Barroco hispano-portugués, desafortunadamente hoy relegada al olvido3. Las obras principales de este autor luso, afincado un tiempo en la corte madrileña, se mueve entre los ámbitos de lo heroico y lo laudatorio: desde el género del epos mitológico, pasando por los cauces encomiásticos del epitalamio o de la poesía descriptiva. Como ha señalado la crítica, los versos heroicos del escritor lisboeta reflejan en numerosos pasajes el influjo de las obras mayores de Luis de Góngora ${ }^{4}$, ya se trate del amplio relato mítico de la Gigantomachia (Lisboa, Pedro Crasbeeck, I623, reeditada en I626 y I628), ya del estro himenaico del Templo da Memoria (Lisboa, I635) o bien de las composiciones recogidas en las Obras varias al Real Palacio del Buen Retiro (Madrid, I637).

Desde el punto de vista político-cultural, Galhegos es un escritor que se mueve en el conflictivo ámbito de la Monarquía Dual (I580-I640). Tras la rebelión del duque de Braganza, el poeta no dudó en cambiar de lealtades y, de hecho, llegó a ocupar un cargo en la nueva corte lisboeta de Juan IV5.

3 Es de obligada consulta el panorama general que José Adriano de Freitas Carvalho ha publicado en fechas recientes sobre «La formación del Parnaso portugués en el siglo XVII. Elogio, crítica e imitación» (2007).

4 Sobre el gongorismo en Portugal, puede consultarse a Ares Montes, (1956) y Cebrián (I999, en especial, sobre Galhegos, véanse las páginas I55-I56).

5 En una entrada del Catálogo razonado biográfico y bibliográfico de los autores portugueses que escribieron en castellano, Domingo García Peres daba una escueta noticia biográfica del autor: «Nació en Lisboa en I597, hijo de Simón Rodríguez de Gallegos y de Gracia Mendes Mourado. Enviudó y se ordenó de presbítero, residiendo por algún tiempo en Madrid. Figuró entre los poetas de aquella centuria y contrajo amistad con Lope de Vega, que no lo olvida en su Laurel de Apolo. Escritor de vigorosa imaginación y elegante estilo, dejó obras excelentes que no merecen el desdén de sus paisanos. Lástima que se dejase llevar de la pasión o de la envidia 
Ahora bien, varios años antes de decantarse a favor de la independencia lusa, a instancias del poderoso don Diego Soares, Secretario de Estado y Miembro del Consejo de Portugal, Manoel de Galhegos puso su pluma al servicio de don Gaspar de Guzmán, conde duque de Olivares, dando a las prensas un libro titulado Obras varias al Real Palacio del Buen Retiro ${ }^{6}$. Destacaban en aquel volumen epidíctico dos amplias composiciones: la Silva topográfica (de la que vamos a analizar varios fragmentos) y las Sextas rimas, un texto muy poco citado por la crítica, mas no por ello carente de interés.

Ante el gran dispendio económico que supuso la «fábrica del Retiro», la opinión pública se mostró dividida: los partidarios del régimen olivarista secundaron los designios del privado, cerrando filas en torno al proyecto, mientras que los detractores criticaron acerbamente la sangría económica que ello suponía, en medio de las guerras en curso (Brown y Elliott 2016)7. De hecho, en el entorno portugués, poco antes de que Galhegos abordara la redacción de los versos encomiástico-descriptivos, figuras como el conde de Ericeira, Antonio Veloso de Lyra y Antonio de Sousa Macedo habían criticado duramente los planes edilicios de don Gaspar de Guzmán ${ }^{8}$. Argumen-

hasta aparecer como crítico y émulo de Camoens, según nos lo cuenta don Francisco Manuel de Melo en su Hospital de las letras (página 308), y que no escapase del contagio gongórico, que desluce a veces sus brillantes dotes. De regreso a su patria, después de la emancipación de Portugal en I640, fue admitido en Palacio como Capellán y en noviembre de I64I obtuvo el privilegio de publicar Gacetas. Suyas son las de aquel tiempo y muchas de las relaciones que entonces con frecuencia salían sobre los sucesos de actualidad. Murió en 3 de junio de I665" (García Peres I890: 246). Para mayor información, véase Martins (1964).

6 Sobre los poetas que elogiaron el régimen del valido, véase la importante contribución de Carreira (2016, en concreto, aborda la figura de Gallegos en p. 44I).

7 Conviene traer a la memoria que la primera aportación encomiástica de cierto calado fueron los Elogios al Palacio Real del Buen Retiro escritos por algunos ingenios de España, recogidos por don Diego de Covarrubias y Leyva, Guarda Mayor del Sitio Real del Buen Retiro, Madrid, Imprenta del Reino, I635. No es baladí que la entera obra estuviera dedicada «Al ilustrísimo y excelentísimo señor don Gaspar de Guzmán, mi señor, conde duque de Olivares». En el tomo participaron algunos de los ingenios más granados del aula regia: el maestro José de Valdivielso, Luis Vélez de Guevara, Juan Pérez de Montalbán, Antonio de Solís, Juan Pablo Mártir Rizo, el cronista real José Pellicer de Salas y Tovar y el dramaturgo Felipe Godínez. Junto a ellos figuran otros cortesanos hoy menos conocidos y encomiastas originarios de otras ciudades (como Toledo o Zaragoza): Plácido Carrillo, Marcos Ruiz de Molina, Rafael Guillén del Castillo, Diego Pellicer de Salas y Tovar, Luis Ramírez de Arellano, Antonio Pellicer de Tovar y Abarca, Diego de Andosilla, Juan Duque de Estrada y Guzmán, Gaspar Dávila, Juan de Solís, Juan de la Barreda, el maestro Gabriel de Roa, Gaspar de la Fuente Vozmediano, Jusepe de Vargas, Alonso Pérez de las Cuentas y Zayas, Diego de Zurita y Mendoza, Pedro Rosete Niño, Ana Ponce de León, Juan de Vidarte, Andrés Carlos de Balmaseda, Antonio de Medina y Fonseca, Jacinto Isola y Juan de Paredes. Sin duda, la composición más destacada del entero volumen es el Panegírico al Palacio Real del Buen Retiro, ambicioso poema en octosílabos del cronista José Pellicer de Salas. Precede a la pieza poética la dedicatoria a «don Jerónimo de Villanueva, comendador de Villafranca en la Orden de Calatrava, del Consejo de su majestad, su Secretario de Estado y Protonotario de los Reinos de la Corona de Aragón».

8 Sobre los detractores y el entorno de la contestación anti-olivarista, véase el brillante 
taban ellos que la nueva morada real se había construido con la sangre de los pobres, descuidando la conservación de los santuarios y lugares sacros, sangrando lastimosamente los tesoros que llegaban en las naos portuguesas. Por otro lado, desde el plano artístico, tampoco puede olvidarse la irrisión del programa iconográfico de la nueva residencia del monarca, difundida en la época a partir del panfleto titulado Quadros que mandarao a Sua Magestade para porem hua Sala o Bom Retiro. En esta suerte de pasquinadas antiolivaristas, se llamaba asimismo la atención sobre el papel jugado por Diogo Soares, acusándole de poner a la venta cargos y prebendas del Reino de Portugal con el propósito de obtener fondos para la corte madrileña, destinados a la ambiciosa obra (Schaub 2001: 56-57).

Por cuanto ahora nos atañe, conviene recalcar cómo las sextinas narrativas que el poeta bilingüe dio a conocer en la segunda parte del tomo constituyen una muestra muy elocuente de poesía política, ya que se configuran al modo de una combativa apología en la que justifica con toda suerte de argumentos la necesidad y la conveniencia de la edificación del nuevo palacio, a pesar de las contrariedades sufridas por el país en el conflicto bélico y la difícil situación económica ${ }^{10}$.

panorama trazado en Schaub (200I).

9 Resumo en este párrafo el contenido de la nota 59 de esta monografía.

IO La composición se rotula escuetamente como Sextas rimas y está integrada por 5 I estrofas (306 versos). Desde el arranque del poema, el autor finge ser portavoz de los pensamientos del rey (vv. I-I2): «La ignorancia plebea contemplando / el son de tanta caja belicosa, / viendo en el campo al ínclito Fernando / y a toda España en guerras cuidadosa, / pregunta cómo en la marcial tormenta / del Retiro la fábrica se aumenta. / Mas agora mi Musa, respondiendo / y dando la razón que el vulgo ignora, / explicará lo que elevado entiendo / y en mis versos Filipo hablará agora, / que para responder el soberano / ha menester la voz y el labio humano» (Galhegos I637: fol. I8 r.). Los arcanos del poder escapan al vulgo maldiciente, de ahí que sea necesario a los ingenios más preclaros iluminar las razones profundas de la acción política (estrofa VII): «No se percibe una razón de estado / si se investiga solo en lo aparente. / De un gobernar, de un discurrir sagrado / no se ven los misterios fácilmente, / que nunca en las acciones hay grandeza / si, entendidas, no agotan la agudeza» (Galhegos I637: fol. I9 r.). Las guerras del norte no pueden alterar los designios del monarca, ni retrasar sus gustos, ya que ello redundaría en una pérdida de reputación y, en cierto modo, podría verse como una victoria del enemigo rebelde (estrofas XI-XII): «Después que un rey de España al mundo muestra / que fabricar desea un edificio / y cuando en él tanta ingeniosa diestra / acrisola del arte el ejercicio, / no es bien que el gusto real turbado pare, / aunque el abismo guerra le declare. / ¿No consideras, bárbaro plebeo, / que si esta insigne fábrica cesara / el Norte no quisiera más trofeo, / ni a más laurel su ejército aspirara? / Que hacer parar con guerra un tan pomposo / asombro es ser de asombros victorioso» (fols. I9 v.-20 r.). De hecho, conviene proseguir con la 'fábrica del Retiro', ya que a la postre será un magnífico monumento de las venideras victorias sobre los insurrectos (estrofas XIII-XIV): «No es de esta ilustre máquina el aumento / estorbo de la guerra, antes reparte / el excelso Guzmán vario talento: / aquí de la pintura, allí de Marte / y, armado, el Español muros destruye / cuando diestro pirámides construye. / Y pues al tiempo que el Retiro crece / el jinete andaluz la tierra bate / y en los rebeldes campos obedece / a la tirana ley del acicate, / deja que este edificio se levante, / que ha de ser de esta guerra arco triunfante» (fol. 20 r.). El esplendor del nuevo palacio es un reflejo de la gloria y poder del monarca, por ese 
Tras iluminar brevemente el convulso panorama político en el que se insertó la escritura de Galhegos, conviene subrayar ahora que la Silva topográfica al Buen Retiro constituye un elaborado alegato a favor del rey, su todopoderoso valido y el nuevo palacio. El entramado laudatorio del poema descriptivo incluía una notable cadena de encomios (directos e indirectos) en los que el laudator ensalzaba a cuatro figuras de rango decreciente: el monarca Felipe IV, el conde-duque de Olivares, el secretario de estado don Jerónimo de Villanueva, el pintor y ujier de cámara Diego de Silva y Velázquez.

En esencia, la entera Silva topográfica al Buen Retiro podría definirse como una amplia composición de signo laudatorio ( 555 versos), redactada a la mayor gloria del nuevo palacio y jardines de Felipe IV ${ }^{\mathrm{II}}$. Como avanza el título mismo, se trata de una combinación libre de heptasílabos y endecasílabos de estilo culto. La compleja muestra de descriptio loci se organiza conforme a una dispositio tripartita, que responde a los modos de enunciación empleados:

I- Marco inicial: encuentro de dos deidades fluviales (el Manzanares y el Tajo) que acuden a ver el suntuoso palacio y los espléndidos jardines que lo circundan (vv. I-34)

II- Discurso del dios-río Manzanares (vv. 35-537)

motivo conviene que se concluya la edificación, para imponer respeto y miedo a los enemigos (estrofas XLIII-XLIV): «Mas no hay discurso, no hay razón, no hay prueba / como el gusto de un rey: triunfe el Retiro, / mida corriendo por distancia nueva / del horizonte universal el giro, / no suspenda Filipo sus deseos, / que no se ha menester a sus trofeos. / Porque si el brío tiene dilatada / la esfera y si el monarca vence ausente, / la regia majestad imaginada / tal vez se hace temer más que presente / y no hay regalo que a Filipo estorbe / el ser para su imperio estrecho el orbe» (fol. 25 r.).

II El 25 de junio de I637 otro ingenio lusitano afincado en la corte, el polémico Manuel de Faria y Sousa, firmaba la Aprobación del tomo. Allí dedicaba a Galhegos el siguiente elogio: «Ya antes de que Vuestra Merced me mandase ver estas Varias Rimas al Real Palacio del Buen Retiro, tenía yo noticia de ellas, porque lo que escribe su autor antes de que se publique ya suena; y apenas suena cuando todo buen oído se admira y la admiración común ya no es gracia, sino deuda a su pensar, a su disponer, a su discurrir y a sus versos y números. Y el ruido que éstos han hecho solo con mostrarlos a pocas personas ya había llegado a mis oídos, ayudando también a esto la materia que el poeta eligió, por ser ella en sí también sonante, que es la espantosa fábrica del Buen Retiro (aun así no bastante para esfera de nuestro gran Planeta Cuarto), benemérita de que todos los ingenios tan levantados como este se empleen en su descripción y en sus elogios por varios títulos» (I637). El erudito portugués también apuntaba en ese documento paratextual el elogio que se brinda desde tales páginas al primer ministro de Felipe IV: «Pasa el poeta a celebrar el artífice de esta [fábrica], que propiamente es el Excelentísimo Señor Conde Duque, a cuya mano política debe palacio el poder ser visto y la campaña desierta de San Jerónimo el verse vuelta un paraíso terrestre, dejando atrás las memoradas viñas con que Italia nos acusaba de incultos y haciendo que España saliese de la barbaridad gótica en que hasta ahora vivió en esta parte». 
III- Cornice final: los dos númenes regresan a su morada, tras haber admirado el regio edificio y el amplio jardín (vv. 538-555)

En la sección central del poema se utiliza el recurso clásico de la sermocinatio de una divinidad fluvial para acometer el elogio. Dentro de tal discurso en estilo directo, la detallada pintura en verso de la nueva residencia real se articula en varias partes:

II. I. Presentación general del edificio y parangón con memorables obras antiguas, según la estrategia retórica del sobrepujamiento (vv. 35-54)

II. 2. Descripción de la plaza de acceso, presidida por una estatua de Carlos V (vv. 55-72)

II. 3. Galería de pinturas y Salón de Reinos (vv. 73-358)

II. 4. Descripción del jardín (parte primera): catálogo de flores y plantas (vv. 359-43I)

II. 5. Descripción del jardín (segunda parte): fuentes y estanque (vv. 432-460)

II. 6. Descripción del jardín (parte tercera): el parque de las fieras (león, tigre, oso, jabalí) (vv. 46I-499)

II. 7. Epílogo: el dios río dirige la alocución al «magnífico Guzmán» (vv. 50o537)

Tal como se aprecia en el esquema, la evocación de las delicias del jardín ocupa tan solo una cuarta parte del poema (I4I versos de un total de 555). De forma significativa, la sección consagrada a la colección artística supera a aquella en extensión, ya que más de la mitad del texto se dedica a loar los numerosos lienzos que alberga el palacio (286 versos de 555). Obviamente, por motivos de espacio no podremos dar cuenta detallada de todos los aspectos relevantes que se asocian a la écfrasis dentro de la silva. Con todo, intentaremos exponer algunos aspectos centrales en tan demorado ejercicio de transposición de arte $^{12}$.

En primer lugar, podría sostenerse con algún fundamento que el dispositivo epidíctico alcanza un alto grado de refinamiento merced a diferentes juegos compositivos. De hecho, una parte destacada de los loores de Felipe IV se plantea de manera indirecta. Así Galhegos se vale sutilmente de la écfrasis para exaltar la uirtus militar del rey: durante su deambular por los diferentes enclaves palaciegos, el poeta-espectador centra su atención en el retrato ecuestre del monarca, ubicado en un lugar principal del Salón de

I2 Baste recordar como definiciones afines de la voz écfrasis (o transposición artística): la de James A. W. Heffernan («representación verbal de una representación visual») y la de Victoria Pineda («descripción literaria de una obra de arte visual»). Para más información sobre la historia y matices de este concepto, central en el orbe inter-artístico, cabe remitir a la monografía Écfrasis: visión y escritura (Ponce Cárdenas 2014: 13-23). 
Reinos. Tal como ha señalado la crítica, en este lienzo velazqueño (Bodart 2OII: 272-273):

La citation flagrante du modèle de Titien est adaptée aux codes de représentation du bon gouvernement: sur un vaste fond de paysage, dépourvu de toute référence topographique, le roi, au visage impassible, le regard tourné vers le lointain, brandit d'une main le bâton de commandement et dirige de l'autre un puissant et fougueux destrier, aux naseaux frémissants, qui exécute sous ses ordres une courbette. La toile s'insérait dans l'impressionnant décor du Salón de Reinos qui comprenait notamment une série de portraits équestres dynastiques, également de la main de Velázquez, et douze grandes toiles figurant les principales victoires des généraux de Philippe IV peintes par différents artistes [...]. Le programme iconographique mettait ainsi en scène la dichotomie consommée entre la souveraineté politique, incarnée par le roi domptant son destrier, et l'exercice militaire désormais délégué aux capitaines de la couronne.

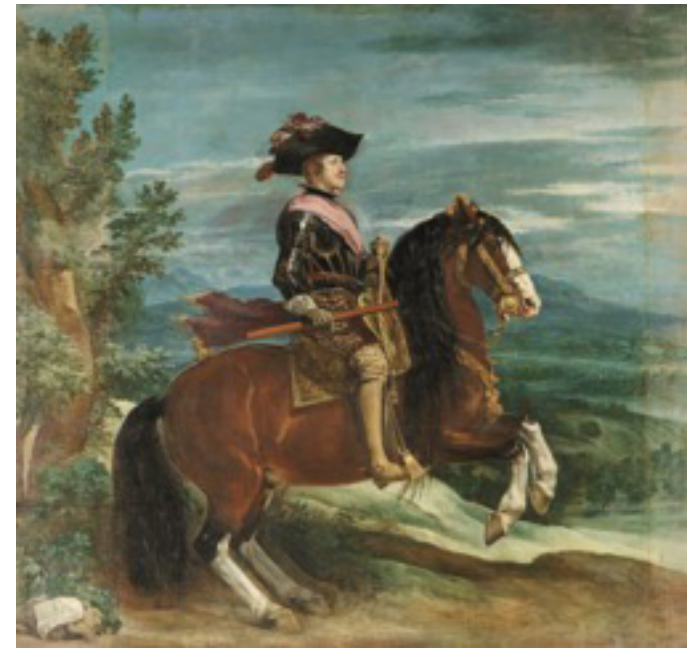

Diego de Silva y Velázquez, Retrato ecuestre de Felipe IV, I634-I635.

Óleo sobre lienzo, 305,5 x 317,5 cm. Museo del Prado.

Sobre el modélico patrón del retrato de Carlos $V$ en Mühlberg, el pintor sevillano «honra a la vez» a la figura imperial y a Tiziano. De alguna manera, Velázquez refuerza «la condición jeroglífica del modelo» y presenta al monarca de perfil. En tanto que el césar «Carlos cabalga al paso», el rey Felipe IV «ejecuta sin esfuerzo una levada, maniobra difícil de alta escuela que pone de relieve su dominio de la montura y evoca la metáfora del buen gobierno» (Brown 1999: 58). 
La efigie del soberano se ensalza en un pasaje ecfrástico de especial interés (vv. 79-98):

\author{
Entra en ese Salón y alegre mira \\ la copia de Filipo, que pendiente \\ adorna de esta puerta lo eminente. \\ Contempla el fuego que en sus ojos gira, \\ considera que airado \\ en jinete veloz se ostenta armado. \\ Si así le viera el belga en la campaña \\ al Imperio de España \\ se rindieran las turbas rebeladas, \\ en rayos de decoro fulminadas. \\ $¡ O h$, rey esclarecido! \\ ¿Vos de grabado acero guarnecido? \\ ¿Vos con bastón, en cuerpo y oprimiendo \\ de un castaño andaluz la inquieta espalda? \\ Sin duda el campo cría \\ laureles de esmeralda; \\ sin duda aún el horrendo \\ gigante con sacrílega osadía \\ bate la empírea esfera \\ y vuestro amparo Júpiter espera.
}

Sobre el telón de fondo de la guerra en Flandes, la soberbia estampa ecuestre del Rey Planeta se asocia alusivamente a la figura olímpica de Jove, ya que podría «fulminar» en «rayos de decoro» a las «turbas rebeladas» del «belga». La lucha del soberano de la Casa de Habsburgo contra los rebeldes septentrionales se plasma entre heptasílabos y endecasílabos bajo la aureola legendaria («con sagrílega osadía / bate la empírea esfera») de una Gigantomaquia. La mera contemplación de la «copia de Filipo» ataviado como caudillo militar provocaría que «se rindieran las turbas rebeladas» en los Países Bajos.

Más allá de la laus regia plasmada mediante una significativa transposición de arte, la entera Silva topográfica recalca la idea de que todos los rincones del admirable recinto entonan los loores del soberano. Galhegos seguiría en ello el modelo latino de las silvas de Estacio, tal como puede apreciarse -por espigar un solo ejemplo significativo- en la musical evocación del gran estanque (vv. 437-444):

En numeroso estanque suavemente

deja domar Neptuno su tridente, que aquí con dulce estilo

bebió el Arte a sus ondas lo tranquilo, lo fresco, lo agradable, lo sereno 
y, en agravio del piélago Tirreno, cantando encomios a Filipo suaves son las Sirenas de este mar las aves.

Tal como pone de manifiesto el breve pasaje, todo en el suntuoso ámbito del nuevo palacio y sus espléndidos jardines sirve para ensalzar las virtudes del rey planeta: «cantando encomios a Filipo suaves».

Desafortunadamente no podemos desarrollar aquí la interesante cuestión del «tema dinástico» que presidía los lados cortos del Salón de Reinos (Brown 1999: 134), pues flanqueando ambas puertas allí mismo se exhibían -además de la efigie del monarca reinante- los retratos de sus padres (Felipe III y Margarita de Austria) y los de su esposa (Isabel de Borbón) y el príncipe heredero (Baltasar Carlos). Como era de rigor, esos otros lienzos también fueron objeto de un elaborado encomio en la silva descriptiva de Manoel de Galhegos $^{13}$. En suma, circundado por la serie de los triunfos militares, las hazañas de Hércules y los otros retratos ecuestres, la efigie del Rey Planeta «operaba en dos niveles de significado. Mostraba al monarca como general victorioso, responsable último de los doce hechos de armas pintados en los muros largos y, señalando otro capítulo glorioso en la historia de la dinastía, identificaba a Felipe como agente de su permanencia» (Brown I999: 134).

\section{El poeta en la galería: Rubens, Reni, Velázquez}

Más allá de la sucinta reflexión en torno al retrato velazqueño del monarca exhibido en el Salón de Reinos, desde el punto de vista de las relaciones inter-artísticas, otro de los puntos de interés que presenta la Silva topográfica al Buen Retiro es la exaltación del ars pictorica ${ }^{14}$. En efecto, en esta composición descriptivo-laudatoria Galhegos incorporó un significativo elenco de grandes maestros, cuyos lienzos podían admirarse en las diversas estancias de palacio («salas, galerías, retretes, corredores»). Allí se dan cita nombres tan eximios como los de Miguel Ángel, Palma il Vecchio, Paolo Veronese, Giacopo Bassano, Tiziano Veccellio, Eugenio Cajés, Juan Bautista Maíno, José de Ribera o Vicente Carducho, por espigar tan solo algunos de los principales. Podemos ver tal nómina en el siguiente pasaje (vv. 226-243):

I3 A la efigie de la reina se consagran los versos 99-II3; a la del príncipe Baltasar Carlos, los versos II4-II9; a los de la real pareja que conforman Felipe III y Margarita de Habsburgo los versos I20-I35 (Galhegos I637: fols. 3 r.-v.).

I4 Una admirable visión de síntesis en torno a las «Las colecciones de Felipe IV» se ofrece en Morán y Checa (1985, en pp. 25I-282). El papel de «Felipe IV como mecenas y coleccionista» ha sido objeto recientemente de otra importante reflexión de Brown (2005). 


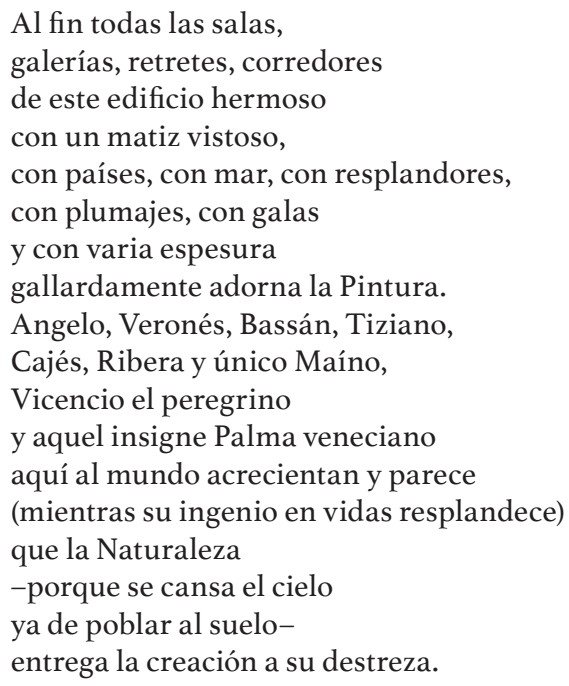

Gracias a la reproducción mimética del Arte («países», «mar», «varia espesura»), en aquel selecto ámbito palaciego toda la Naturaleza aparece reproducida a través de diversos cuadros, ejecutados por los creadores más célebres de España e Italia, tanto renacentistas como barrocos ${ }^{15}$. Por otra parte, la selección de pintores que plantea el pasaje de Manoel de Galhegos puede ponerse en paralelo con la reducida lista de maestros que exaltó Francisco de Quevedo en un conocido fragmento de la silva titulada El pincel (vv. 67-IOo): Tiziano, Rafael, Miguel Ángel y Velázquez (Cacho 2012: 20I).

Frente a la alabanza genérica -que dispone mediante un recurso tan socorrido como el del catálogo-, mayor interés reviste la breve selección de piezas pictóricas evocadas en algunos pasajes. De hecho, en la Silva topográfica se ponderan mediante la transposición de arte diversas piezas de Luca Cambiaso, Pedro Pablo Rubens, Frans Snyders, Guido Reni y Velázquez. Veamos ahora cómo procede el encomiasta en tales écfrasis. El primer testimonio se refiere, de forma algo sucinta, a uno de los temas dilectos de la pintura sacra barroca: las lágrimas de Santa María Magdalena (Gallego Zarzosa 20I2, Portmann 20I4). En apenas dos endecasílabos Galhegos exalta el marcado pathos de un lienzo de Luca Cambiaso (vv. 244-245): «iNo ves con qué agonía, con qué afeto / llora la Magdalena de Luqueto?» ${ }^{16}$. El poeta

I5 Para otros listados en elogio de artistas, esbozados por Quevedo y Lope al modo de «Parnasos pictóricos», puede verse Sáez (2015: 8I-IOI).

I6 Desafortunadamente, no hemos podido identificar con certidumbre cuál puede ser la obra concreta a la que se refiere el autor luso. Ahora bien, desde el punto de vista de la transposición de arte y su elaboración conceptual, se puede comparar la sintética referencia de los dos versos de Galhegos con el soneto incluido por Giovan Battista Marino en la Galeria, 
centra su atención en la representación del dolor de esta figura penitencial, que consigue conmover al espectador.

Frente a la rauda alabanza inspirada en la imagen sacra del artista italiano, mayor enjundia posee el elogio de un lienzo de tema histórico: La muerte de Séneca, atribuido a Ruben $\mathbf{s}^{17}$.

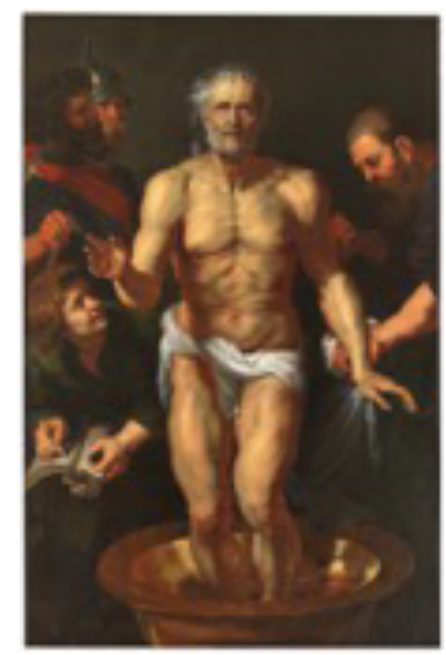

Copia del taller de Pedro Pablo Rubens, La muerte de Séneca, I6I2-I6I5.

Óleo sobre lienzo, I8I x II9,8 cm. Museo Nacional del Prado. Catálogo Po3048.

La contemplación de la venerable escena de historia romana sustenta la siguiente laudatio (vv. 246-260):

bajo el título de Maddalena piangente di Luca Cangiasi: «Finta dunque è costei? Chi credea mai / animati i color', vive le carte? / Finta certo è costei, ma con tal arte / che l'esser dal parer vinto è d'assai. / Oh di che dolce pianto umidi i rai / al Ciel, dov'è di lei la miglior parte, / volge, e le chiome intorno ha sciolte e sparte, / altrui bella cagion d'eterni lai! / Oh come in atto e languida, e vivace, / dove manca a le labra, aver spedita / par negli occhi la lingua, e parla, e tace. / E par tacendo dir: -'Già spirto e vita / diemmi il Pittor , ma l'anima fugace / fe' poi da me col mio Signor partita'» (Marino 1979: tomo I, 70).

I7 En verdad el gran artista flamenco pintó únicamente la versión de esta pintura que hoy día se custodia en la Alte Pinakothek de Múnich, en tanto que el cuadro que se exhibía en el palacio del Buen Retiro (que pertenece hoy a los ricos fondos del Museo del Prado) debe identificarse como una copia - de notable calidad - surgida del taller del genio flamenco. En el inventario de la testamentaría de Carlos II (Buen Retiro, I70I-I703) se refieren así a la obra: «una pintura de dos varas y tercia de alto y varia y tercia de ancho, de la muerte de Séneca en el baño. Copia de Rubens. Con marco tallado y dorado, tasada en cuarenta doblones» (número 409). 


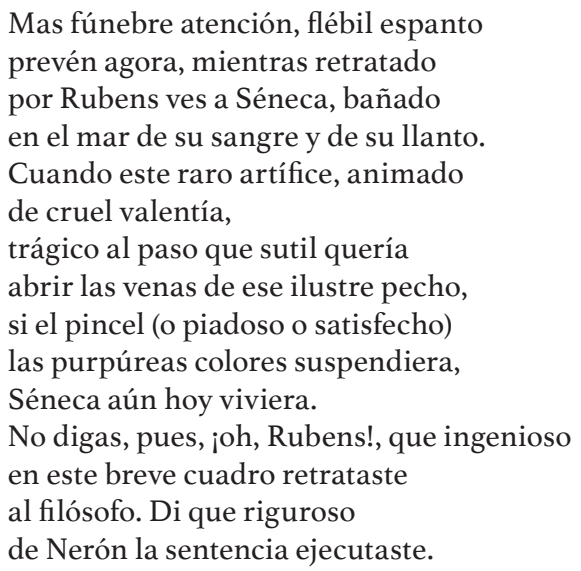

Conforme a los cauces más trillados de la exaltación demiúrgica, el talento de Pedro Pablo Rubens es tal que resulta capaz de dotar de vida a las figuras que pinta. Ahora bien, por contraste, al plasmar la imagen de un Séneca moribundo, reproduciendo mediante "purpúreas colores» la sangre que fluye, lejos de actuar como un 'pictor deus' obra casi como un ejecutor. El pintor no confiere así vida a la efigie del filósofo, sino que lo condena a una muerte lastimosa: el óbito se cumple eternamente por obra y gracia de la exquisita representación pictórica.

Tras los versos consagrados a dos pinturas de historia, en la doble modalidad sacra (Luca Cambiaso) y profana (Rubens), la atención de Galhegos se desplazará posteriormente hacia otro género de menor entidad, el más humilde en la escala de la pintura académica: la Naturaleza muerta. 


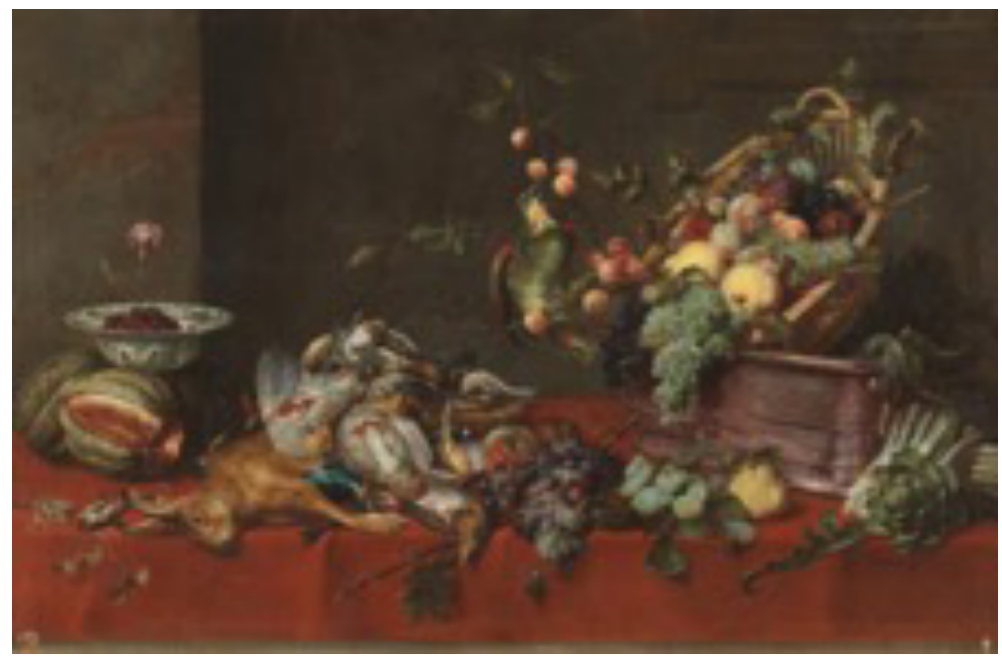

Frans Snyders (Po 1768), Bodegón (óleo sobre lienzo), I2I x I83cm. Colección Real.

El elogio se dedica ahora a los lienzos de Frans Snyders (1579-1657), uno de los bodegonistas favoritos de la corte del Rey Planeta (vv. 26I-268):

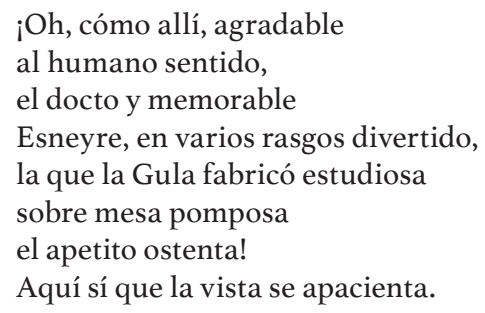

Los diversos manjares del lienzo, artificiosamente colocados sobre una suntuosa mesa de banquete, se disponen en el verso como el apetecible conjunto de «lo que la Gula fabricó estudiosa». Por otra parte, la exhibición de la abundancia y el lujo se refleja poéticamente en vocablos del tenor de «ostenta» o en el calificativo «pomposa».

A juicio de Galhegos, la visión de alimentos y objetos propia de la $\mathrm{Na}$ tura morta resulta «agradable / al humano sentido». Tal exaltación del arte del bodegonista no suele ser muy frecuente en la época. Quizá podría aducirse como paralelo el epigrama que Lope de Vega dedicara a Juan Vander Hamen Valderrama, ensalzando su talento como autor de dos modalidades afines de bodegón (denominados, respectivamente, 'frutero' y 'florero'): «[Naturaleza] dijo que vuestro ingenio peregrino / le hurtó para hacer frutas sus 
pinceles; / que no pintáis, sino criais claveles, / como ella en tierra, vos en blanco lino» (Vega 1989: I2I7; Sánchez Jiménez 20II: 278-280).

Gracias a la capacidad ilusionista del arte, el atractivo sensorial de los lienzos de Snyders parece saciar el hambre de cuantos los contemplan. Ahora bien, desde el punto de vista de la tradición literaria, el endecasílabo que sirve de cierre ponderativo («Aquí sí que la vista se apacienta») podría verse a la manera de un sutil homenaje a una troquelación virgiliana (Aeneis I, v. 464 «atque animum pictura pascit inani»), imitada durante el Quinientos en un dístico de la garcilasiana Égloga segunda (vv. I326-I327 «Él, lleno de alborozo y d'alegría / sus ojos mantenía de pintura») y en un epigrama neolatino de Arias Montano («Dum reficit pictura oculos»). Ya en los albores del Barroco puede apreciarse un eco similar en un verso de un soneto laudatorio gongorino, redactado en I606 en honor del marqués de Ayamonte (v. I2): «Cebado vos los ojos de pintura» (Ponce Cárdenas 2013: 144-157).

Otra de las imágenes, perteneciente a la historia legendaria de la antigua Roma, le servirá a Galhegos para ensalzar el virtuosismo de Guido Reni (vv. 269-276):

Si ensangrentado el pecho cristalino
(en esa tabla donde Guido muestra
el poder milagroso de su diestra)
viera a Lucrecia el bárbaro Tarquino,
de su tirano amor se arrepintiera
y a la lástima tanto se rindiera
que en lágrimas el alma distilara
y la piedad su culpa castigara.

Ante todo, cabe plantear algunas dudas sobre a cuál de las versiones de esta escena trágica pintada por el artista boloñés se refiere, ya que en España se conservan diferentes versiones de Lucrecia, atribuidas tanto a Guido Reni como a los discípulos que trabajaron en su taller. 


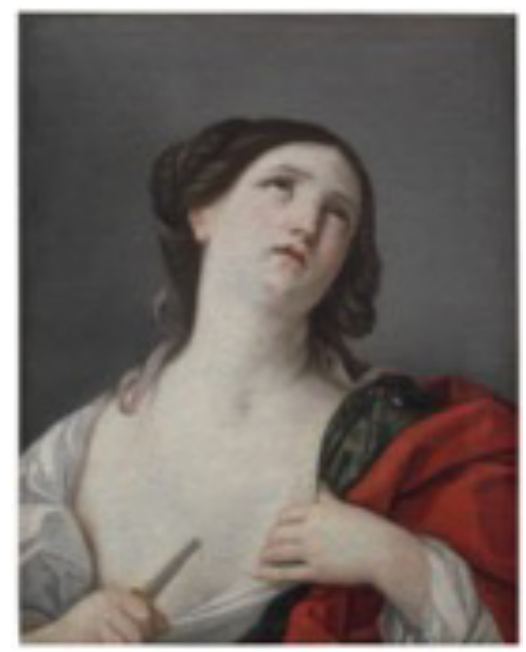

Taller de Guido Reni, Lucrecia dándose muerte, primera mitad del siglo XVII.

Óleo sobre lienzo, 72 x $57 \mathrm{~cm}$. Museo del Prado. Catálogo Poo2o8.

A modo ilustrativo, podemos fijar nuestra atención en esta obra de pequeño formato, en la que se pone el acento en el delicado candor del torso ebúrneo. El extremo de la daga comienza a hundirse en las níveas carnes de la virtuosa dama patricia y una gota de sangre brota de la herida incipiente. Quizá tal detalle (o el de un lienzo muy similar) podría reflejarse líricamente en el arranque de la transposición artística: «ensangrentado el pecho cristalino». Desde el plano conceptual, el poeta-espectador recurre nuevamente a la moción de afectos: si el despótico Tarquino el Soberbio hubiera contemplado tan lastimosa escena, no habría dado rienda suelta a su sensualidad y se habría evitado el trágico final.

Los elogios -más o menos estereotipados- que Manoel de Galhegos dedica a las pinturas de Cambiaso, Rubens, Snyders o Reni empalidecen ante el largo y suntuoso pasaje encomiástico que este ingenio cortesano tributa a Diego de Silva y Velázquez. Al comienzo de tal alabanza, el laudator concede al pintor de cámara el primado entre los artistas de su tiempo (vv.277-294):

Mas dime, oh potentado de Neptuno cuya corriente el Aquilón adora y a quien sirven los ríos lusitanos cuando al son de tus ondas importuno la Fama voladora aplicando a su trompa diestras manos grandezas del pincel canta sonora, 
¿no oyes por los vientos

repetidos portentos

del gran Diego Velázquez?, ¿en tu orilla

no escribes con carácter cristalino

el nombre de este ingenio peregrino?

Pues tanto a sus colores obedece

la Parca rigurosa

que su pincel, artificioso cetro

digno de heroico metro

la monarquía alcanza milagrosa

de cuanta vida en cuadros resplandece.

Gracias a la admirable capacidad de imbuir de vida a sus lienzos, el pincel de Velázquez se erige en el «cetro» que por derecho pertenece a quien «alcanza la monarquía milagrosa de cuanta vida resplandece en cuadros». El dios-río Tajo, con toda justicia, llevará su nombradía hasta las riberas lusitanas. Tal como corresponde al más preclaro de los pintores vivos, el maestro sevillano resulta «digno de heroico metro». Ahondando en dicha idea, en una notable tirada de versos, Galhegos ensalzará la capacidad casi demiúrgica del pintor de cámara (vv. 295-316):

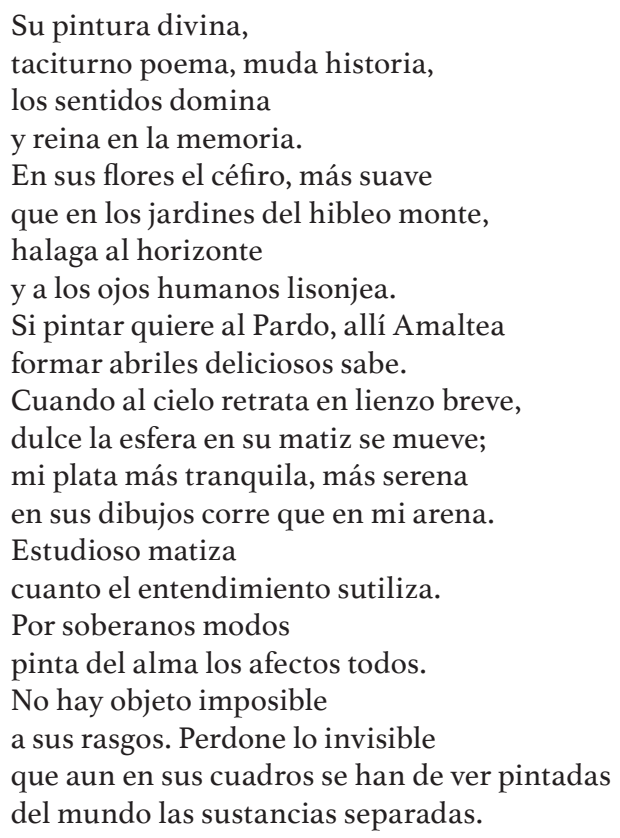


Mediante un sutil ejercicio de variatio, desde el arranque de este fragmento, el encomiasta evoca como de pasada aquella máxima de Simónides de Ceos sobre la «muda poesía» y la «elocuente pintura», plasmando las correspondencias entre ambas artes en una doble equiparación, aplicada al segundo artejo: «pintura divina» = «taciturno poema» / «muda historia» (Rodríguez Posada 20I7). La función del arte es preservar el recuerdo, fijar la efigie para la eternidad, de manera que la perfecta imagen «domina los sentidos» al tiempo que «reina en la memoria». Otro detalle significativo en el encomio del virtuosismo del artista es su capacidad de reflejar, como fondo de numerosos retratos, un paisaje real de forma detallada y verista: «Si pintar quiere al Pardo, allí Amaltea / formar abriles deliciosos sabe. / Cuando al cielo retrata en lienzo breve, / dulce la esfera en su matiz se mueve».

Orillando los cuatro retratos regios (Felipe III y Margarita de Austria; Felipe IV e Isabel de Borbón), descritos convenientemente en la sección consagrada al Salón de Reinos, la primera pintura velazqueña a la que se refiere explícitamente se ha perdido y no parece haber quedado vestigio de ella: Apolo y Marsias (vv. 317-326):

\author{
Este, pues, que hoy sirviendo en el Palacio \\ del Gran Filipo apura su destreza, \\ ocupó de ese lienzo el breve espacio \\ con Apolo y con Marsias. Considera \\ la animada fiereza \\ que en el dios vengativo reverbera. \\ Mira cómo vencido \\ el músico atrevido \\ con el mayor tormento \\ el delito pagó de su instrumento.
}

Frente a la misteriosa obra de pequeño formato y asunto mitológico («de ese lienzo el breve espacio»), se exalta en el siguiente fragmento uno de los cuadros de historia sacra más admirables y grandiosos del pintor. Como apuntara Jonathan Brown,

La túnica de José es un cuadro plenamente, casi ostentosamente, italianizante [...]. Entre las figuras hay un espacio holgado, establecido por una parrilla perspectiva, y ninguna aparece recortada por los hombros ni por la cintura. En las cinceladas formas semidesnudas de los dos hermanos del lado izquierdo se advierte una marcada influencia del dibujo de figuras clasicista, y las actitudes y expresiones están muy calculadas para transmitir el impacto emocional de la revelación de la presunta muerte de José. La iluminación de la escena es mucho más sutil, variando desde las luces fuertes de la izquierda hasta la sombra transparente que envuelve a las dos figuras del término medio. Velázquez demuestra ser un alumno aplicado; en muy poco tiempo 
ha asimilado los cánones y fórmulas del gran estilo de la pintura romana de historia y las sutilezas del colore veneciano sin renunciar a su personalidad. Aunque la obra sea italianizante, sería difícil detectar el influjo particular de ninguno de los pintores italianos del momento (2008: 392-393).

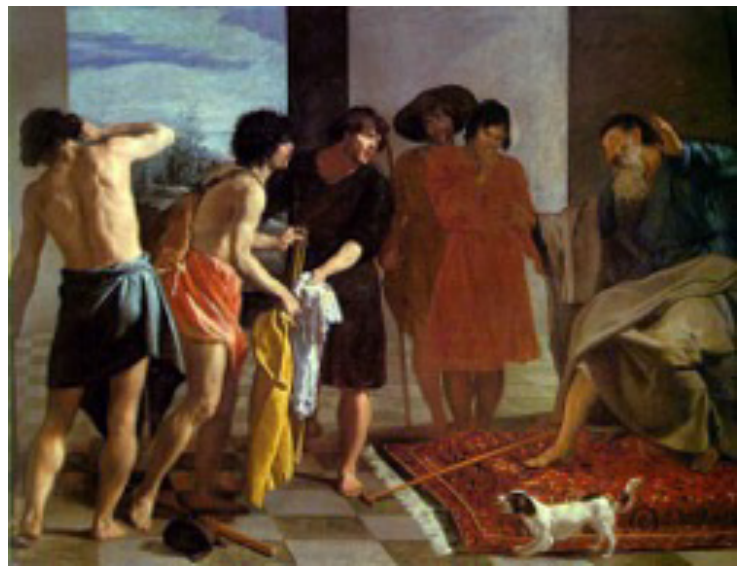

Diego de Silva y Velázquez, La túnica de José, I630.

Óleo sobre lienzo, 223 x 250 cm. Nuevos Museos, San Lorenzo el Real del Escorial.

Como es sabido, cuatro años después de haber pintado en Roma esta ambiciosa obra, «en I634 Velázquez firmó un recibo de mil ducados a Jerónimo de Villanueva por la venta de diecisiete lienzos, éste entre ellos, que pasaron a ingresar en las colecciones reales» (Morán Turina \& Sánchez Quevedo I999: 98). La magnífica pintura adquirida por el Protonotario de Aragón se exhibía originariamente en el recién construido palacio y Manoel de Galhegos la ensalza en los siguientes términos (vv. 327-333):
También estudio de este ingenio raro, obra también de este pincel preclaro es esa tabla donde lastimoso el patriarca Jacob gime en colores y explicando en matices sus dolores fúnebre llora, trágico suspira, mientras de su José la sangre admira.

Frente a los otros lienzos evocados por el cortesano luso, en el caso de esta pintura velazqueña puede cotejarse brevemente la alabanza con otro testimonio del siglo XVII, el del padre fray Francisco de los Santos (Santos I698: 8I r.-v.): 
Muéstrase en la pintura la habitación y casa de Jacob, de edificio fuerte y noble, de capacidad, distancia y altura, con toda proporción; solado el pavimento con piedras blancas y pardas que van en disminución y hacen una dilatación muy espaciosa y larga. A un lado, al principio del lienzo, hay corrida una cortina grande de color morado, vueltas y recogidas las puntas ${ }^{18}$; y debajo, sobre una tarima o grada capaz, levantada algo del suelo, vestida de un alfombra de varios colores y tan perfecta que parece verdadera, está el asiento de Jacob. Allí se representa el santo patriarca, de rostro venerable, de traje llano y decente, mostrando el sentimiento más vivo (a vista de la vestidura ensangrentada) que es imaginable; movido algo del asiento y arrojada a sus pies una muletilla, arrimo de su ancianidad, se mira abiertos los brazos, elevadas las cejas y la frente, vivos los ojos y en ellos todo el corazón lastimado y arrebatado de la sangre que mira, de la desgracia que discurre.

La completa noticia que el padre Santos da del lienzo se detiene, además, en los detalles de todas las figuras, ponderando el virtuosismo técnico de las mismas: «los pastores [...] están pintados con grandísimo estudio y destreza. Los cuerpos de lindas carnes y de miembros alentados y fuertes; las posiciones y planta de mucha diferencia. Uno se ve de frente, otro de medio lado, otro de espaldas y las muestra desnudas, con tal arte y disposición que puede ser ejemplar para la notomía» (fol. 8I v.). Cualquier punto que se analice evidencia a sus ojos la exquisita elaboración de la entera obra: «ella es una pintura excelente, los coloridos, sombras y luces de admirable efecto: mirado todo junto pone admiración» (fol. 82 r.).

Tal como apuntara José Luis Colomer, «lo significativo de la Descripción del padre Santos para contemplar el lienzo romano de Velázquez con la mirada de su primer público es que remite a una manera de entender la pintura como ilustración de su fuente textual, lo que convierte su comentario en una comprobación de la habilidad del artista para plasmar las palabras en imágenes» (Colomer 2007: 154). El prior del Escorial puso el acento en «el reflejo pictórico de las emociones que vivieron los personajes del relato bíblico (Génesis, XXXVII, 3I-33), estableciendo paralelos entre la escena representada y el texto del que procede. La suya es una lectura dramática de esta narración visual: se fija en las "demostraciones de sentimiento" de Jacob, observa los "meneos y acciones" de quien viene a darle la mala noticia, fingiendo uno pesar, otro dolor y tristeza» (Colomer 2007: 154).

Volviendo al campo de la écfrasis, la prosa descriptiva de fray Francisco de los Santos recalca la expresión de los afectos en la figura central del anciano padre («mostrando el sentimiento más vivo [...] que es imaginable»; «vivos los ojos y en ellos todo el corazón lastimado y arrebatado») de ma-

I8 «El cuadro está recortado por los lados, habiendo desaparecido por completo el cortinaje rojo que menciona el padre Santos sobre la figura de Jacob. La composición original se conoce por dos copias antiguas bastante estropeadas» (Morán Turina y Sánchez Quevedo 1999: 98). 
nera similar a cómo lo hacen los siete endecasílabos de la Silva topográfica («lastimoso el patriarca Jacob gime en colores», «explicando en matices sus dolores fúnebre llora, trágico suspira ${{ }^{19}}^{19}$.

Por último, a modo de conclusión de tan extenso encomio, se enlazan simbólicamente las figuras del pintor de cámara y el soberano (vv. 334-358):
Al fin, diversas partes de esta sala este divino artífice guarnece.
Aquí el arte en prodigios se engrandece, aquí fingida flor aroma exhala, aquí partida en almas la destreza y produciendo vidas la pintura ingeniosa procura poblar un hemisferio sin que nada se deba al ministerio de la Naturaleza.
Aquí el arte parece (mientras su valentía pinta vivientes y retratos cría) que al gran Filipo ofrece pueblo más vivo, imperio más durable, pues le elige monarca de lo que a la cuchilla formidable se usurpa de la Parca. ¡Oh, peregrina mano! ¡Oh, pincel soberano! ¡Oh, maravilla rara! Viérase encarecida esta que admiras máquina preclara si aquel matiz que es de sus cuadros vida la copia de mis labios animara.

Quizá no esté de más señalar cómo el elocuente pasaje encomiástico de Manoel de Galhegos actualiza algunas ideas puestas en circulación ya desde el Quattrocento por León Battista Alberti, en el influyente volumen De pictura. Tal como subrayara Edouard Pommier, «pour Alberti la peinture elle-même est pouvoir et que le peintre en personne est détenteur d'un pouvoir impressionnant». A la manera de un demiurgo, «le peintre a le privilège extraordinaire de rendre les dieux visibles et les absent présents: mais il peut faire plus encore: 'faire surgir après de longs siècles les morts aux yeux des vivants'. Le peintre selon Alberti est le maître de l'espace, qu'il domine par ses connaissances scientifiques, et du temps, qu'il transcende par l'exercice d'un véritable ministère de mémoire» (Pommier 2013: 6I). El

I9 Nótese el alto carácter expresivo de la sinestesia: «gime en colores». 
poder creativo del pintor de cámara refuerza el poder político o terrenal del soberano: gracias al genio de Velázquez, que «pinta vivientes y retratos cría», el «gran Filipo» triunfa sobre la Muerte, en tanto monarca de «un pueblo más vivo», de un «imperio más durable» ${ }^{20}$.

En definitiva, más allá de la serie de tópicos que se movilizan en todas las prácticas de la alabanza, conviene recordar que, desde el campo de la historiografía artística, una figura tan autorizada como Javier Portús ha estimado en fechas recientes que la gavilla de versos encomiásticos que Galhegos tributara a Velázquez merece una valoración positiva ${ }^{21}$.

No podemos cerrar este apartado sin antes llamar la atención sobre un dato de cierta relevancia que se aprecia tan solo al comparar el contenido de los Elogios al Palacio Real del Buen Retiro (I635) y de las Obras varias al Real Palacio del Buen Retiro (1637). En el primer volumen nada menos que cuatro sonetos se dedicaron a La recuperación del Brasil (Salvador de Bahía de Todos los Santos), el admirable lienzo que fray Juan Bautista Maíno pintó para el ciclo de triunfos militares del Salón de Reinos. En este primer volumen epidíctico, solo los epigramas de Ana Ponce de León, Andrés Carlos de Balmaseda, el maestro Gabriel de Roa y Alonso Pérez de las Cuentas se refieren a una pintura en concreto, al tiempo que ponen de relieve el «ingenio» $\mathrm{y}$ "grandeza» del maestro de dibujo de Felipe IV. Sin duda, como bien ha recalcado Fernando Marías, «aunque el siglo XVII fue pródigo en poemas encomiásticos de pintores y pinturas, y el propio Maíno había recibido elogios en verso, es difícil encontrar un ejemplo semejante de atención y encomio vario. Como es natural, a los ojos de sus contemporáneos, la obra del religioso debía merecerlos» (Marías 2012: 39). Ahora bien, por contraste, desde la valoración artística de nuestra cronología, resulta clamoroso el silencio que se reserva en aquel tomo para el conjunto de obras de Velázquez exhibidas en el mismo Salón de Reinos: los cinco retratos ecuestres de la familia real y una

20 Los elogios que tributa al genial pintor sevillano podrían compararse a los que algunos años antes le dedicara Quevedo en la Silva al pincel (vv. 85-IOo): «Y por ti el gran Velázquez ha podido, / diestro cuanto ingenioso, / ansí animar lo hermoso, / ansí dar a lo mórbido sentido / con las manchas distantes, / que son verdad en él, no semejantes, / si los afectos pinta / y de la tabla leve / huye bulto la tinta, desmentido / de la mano el relieve; / y si en copia aparente / retrata algún semblante, y ya viviente / no le puede dejar lo colorido, / que tanto quedó parecido / que se niega pintado y al reflejo / se atribuye que imita en el espejo» (Cacho 20I2: 20I-202). 2I «Son muy interesantes, por ejemplo, las estrofas que le dedica Manuel de Gallegos en su Silva topográfica (1637), dedicada al palacio del Buen Retiro. Ahí son descritos algunos de los cuadros del palacio y, aunque menciona a Veronés, Bassano, Tiziano, Cajés, Ribera, Maíno, Carducho, Guido Reni o Rubens, las disertaciones más detenidas y elogiosas son las dedicadas a Velázquez, que queda de esta manera ensalzado por vía de comparación. El texto de Gallegos prueba que Velázquez contaba en su entorno con personajes inteligentes que supieron valorar algunas de las novedades de su pintura, como las atinentes a la ubicación de sus retratos en un entorno natural reconocible» (Portús 20I2: 39-40). 
pieza magistral como La rendición de Breda ${ }^{22}$. Frente a las preferencias de la antología de versos compilada por Diego de Covarrubias y Leyva en I635, podría sostenerse que en las Obras varias al Real Palacio del Buen Retiro, Galhegos asume ciertas distancias, apenas dos años más tarde: en primer lugar, porque apuesta sin ambages por la transposición artística -toda vez que rehuye las vacuas alabanzas genéricas del recinto y, especialmente, del Salón de Reinos-y, en segundo término, porque parece conceder la primacía creativa en el aula regia a Diego de Silva y Velázquez a través de una mesurada Laus Artis, dejando así de lado la figura de Juan Bautista Maíno.

\section{La transposición de arte: entre la alabanza regia y el gesto político}

Como hemos tenido ocasión de ver, la Silva topográfica al Buen Retiro se inserta en un género dotado de perfiles claramente distinguibles. Se trata, ante todo, de un tipo de poesía imbuida de valores visuales, a la que desde antiguo se vincula íntimamente la écfrasis ${ }^{23}$. El elogio del nuevo palacio de Felipe IV se inscribe, pues, en unos parámetros históricos y culturales muy claros: la morada regia del Buen Retiro se erigió en un «poderoso símbolo político y social», ya que no solo servía «como residencia del monarca y como centro de gobierno» sino que «constituía la manifestación más expresiva de las riquezas y la gloria obtenidas a través del dominio de los hombres y las tierras» (Brown y Elliott 20I6). Por consiguiente, la descripción y exaltación de la residencia real serviría, al mismo tiempo, para alabar el poder omnímodo del rey planeta y el buen gobierno de su providente valido; para ensalzar la cultura del monarca y sus inclinaciones artísticas; para loar la riqueza del reino y la gloria de los dominios habsbúrguicos.

22 Tal detalle lo aprecia con perspicacia Fernando Marías: «Sorprendentemente cuando no se cita ni una sola vez a Velázquez, cuatro poemas se le dedicaron a Fray Juan Bautista y su lienzo brasileño» (Marías 20I2:36).

23 Durante el Siglo de Oro, los poemas consagrados a palacios y jardines siguieron el modelo latino imperial de Estacio, en cuyas silvas menudea la descripción de obras de arte. También ofrecían un magistral ejemplo a los poetas de la corte de España las modernas composiciones redactadas en latín humanístico o en italiano. Por espigar algún ejemplo notorio, baste recordar cómo en 1569 Lorenzo Gambara pintaba verbalmente la Villa Farnese de Caprarola, dedicando especial atención a los frescos de Taddeo y Federico Zuccari que allí se localizan (Arcis Caprarola Descriptio). Durante la siguiente centuria, en un estilo ya plenamente barroco, Giovan Vincenzo Imperiale reservaba una sección de Lo stato rustico (editado en I607, reimpreso en I6II y I6I3) a la descripción de la lujosa mansión campestre que su aristocrática familia poseía en la costa de Liguria: la famosa Villa Imperiale, en Sampierdarena. Allí puede leerse la écfrasis de las pinturas parietales de Bernardo Castello (David da muerte a Goliath, Judith y Holofernes, David y el león). De manera similar obraría poco después Giovanni Antonio Liberati con La Caprarola in versi toscani e latini (I6I4), donde se consagra una parte del poema a la transposición artística. 
Desde las páginas de una iluminadora reflexión, en fechas recientes Fernando Marías proponía «ver en las imágenes o en algunas de sus producciones un gesto político que debiera haberlas convertido en un hecho de clara lectura y significación no solo ideológica, sino estrictamente política» (Marías 2012: 17). A zaga de tal valoración, quizá sea lícito pensar que la descripción lírica de algunas imágenes puede asumir también, en un contexto determinado, el valor de un gesto político, la eficacia de un panegírico. La écfrasis de las diversas piezas velazqueñas insertas en la Silva topográfica podría ser un buen ejemplo de ello. En efecto, como artista ubicado en un contexto áulico,

Velázquez no se diferencia de los pintores que le precedieron ni de cuantos trabajaron en las cortes europeas de los comienzos de la época moderna. Pinturas como las ejecutadas para el Salón de Reinos o la Torre de la Parada pertenecen claramente a la categoría de imágenes de glorificación. Su fin era pregonar las regias virtudes del monarca o príncipe y rodearle de un aura de majestad, con arreglo a las normas culturales y políticas de la corte correspondiente (Brown 1999: 58).

Por tanto, la transposición de arte referida a aquellos mismos retratos de aparato podría contemplarse como un reflejo añadido, como un refuerzo de tal «glorificación». En definitiva, tal como Lina Bolzoni apreciara ya en el caso de la tradición italiana del Renacimiento, «il tema della grandeza straordinaria del soggetto rappresentato e dell'artista acquista una valenza politica nelle poesie dedicate al ritratto di un principe» (Bolzoni 2008: 45).

El panorama pictórico que Galhegos despliega en la silva atiende a cuatro géneros: bodegón, paisaje, retrato y cuadro de historia. Como cabía esperar, la visión del poeta-espectador que recorre las salas y galerías de palacio se detiene especialmente en los géneros más altos de la escala académica: el retrato áulico y el tableau d'histoire. Por cuanto se refiere a esta última tipología, en la silva se pondera -una y otra vez- la exacerbada expresión de los afectos, el pathos de tales obras: «¿no ves con qué agonía, con qué afecto llora?», «fúnebre atención, flébil espanto prevén», «raro artífice animado de cruel valentía», «y a la lástima tanto se rindiera que en lágrimas el alma distilara», «esa tabla donde lastimoso el patriarca Jacob gime en colores y explicando en matices sus dolores fúnebre llora, trágico suspira». Según se desprende de tales valoraciones, el connoisseur barroco que camina por la regia morada se siente atraído por la retórica de las lágrimas propia de la imagen secentista, admirando la moción de afectos en los lienzos de tres genios de muy diverso perfil (Rubens, Guido Reni, Velázquez) ${ }^{24}$.

24 Como sintética reflexión sobre la expresión de las pasiones en la pintura del siglo XVII, cabe remitir a Albero Muñoz (2006). 
En suma, de entre los centenares de obras maestras que pendían de los muros del Palacio del Buen Retiro, Manoel de Galhegos realizó una personal selección que, varios siglos después, sigue dando noticia de sus gustos e intereses. A través de ese 'boceto' rimado, el poeta y cortesano luso ha legado a la posteridad algunos datos relevantes sobre la «mirada» del público culto en el aula regia de Felipe IV, así como algunas pistas preciosas sobre los usos y funciones de la écfrasis en el Siglo de Oro.

\section{Bibliografía}

Albero Muñoz, María del Mar, «La pasión por las pasiones en la pintura barroca», En torno al Barroco: miradas múltiples, Murcia, Universidad de Murcia, 2006, pp. I3I-I42.

Ares Montes, José, Góngora y la poesía portuguesa del siglo XVII, Madrid, Gredos, 1956.

Bodart, Diane H., Pouvoirs du portrait sous les Habsbourg d'Espagne, París, Institut National d'Histoire de l'Art, 201 I.

Bolzoni, Lina, Poesia e ritratto nel Rinascimento, Bari, Laterza, 2008.

Brown, Jonathan, «Entre tradición y función: Velázquez como pintor de corte», Velázquez, Rubens y Van Dyck, pintores cortesanos del siglo XVII, Madrid, Museo del Prado, 1999.

-. «Felipe IV como mecenas y coleccionista», El Palacio del Rey Planeta. Felipe IV y el Buen Retiro, Madrid, Museo Nacional del Prado, 2005, pp. 45-62.

-.Escritos completos sobre Velázquez, Madrid, C.E.E.H., 2008.

Brown, Jonathan \& John H. Elliott, Un palacio para el rey. El Buen Retiro y la Corte de Felipe IV, Madrid, Taurus, 2016.

Carreira, Antonio, «El conde duque de Olivares y los poetas de su tiempo», Nueva Revista de Filología Hispánica, LXIV.2, 2016, pp. 429-456.

Caruso, Carlo, «Poesia umanistica di villa», en Feconde venner le carte. Studi in onore di Ottavio Besomi, ed. Tatiana Crivelli, Bellinzona, Edizioni Casagrande, 1997, pp. 272-294.

Cebrián, José, «Góngora, más allá de la raya», En la Edad de Oro. Estudios de ecdótica y crítica literaria, México, El Colegio de México, 1999, pp. I47-I69.

Colomer, José Luis, «De Madrid a Roma: I630. Velázquez y la pintura de historia», Fábulas de Velázquez, Madrid, Museo del Prado, 2007, pp. I33I59.

Elliott, John H., El conde duque de Olivares. El politico en una época de decadencia, Barcelona, Crítica, 1990.

Freitas Carvalho, José Adriano de, «La formación del Parnaso portugués en el siglo XVII. Elogio, crítica e imitación», Bulletin Hispanique, I09.2, 2007, pp. 473-509. 
Galhegos, Manuel de, Obras varias al Real Palacio del Buen Retiro, Madrid, María de Quiñones, I637.

Gallego Zarzosa, Alicia, «María Magdalena y su tratamiento erótico: la Magdalena de Lope», Analecta Malacitana Electrónica, 32, 2012, pp. 42I450 .

García Peres, Domingo, Catálogo razonado biográfico y bibliográfico de los autores portugueses que escribieron en castellano, Madrid, Imprenta del Colegio Nacional de Sordomudos y Ciegos, I890, pp. 246-249.

Hernando Sánchez, Carlos José, «Los jardines de Nápoles en el siglo XVI. Naturaleza y poder en la corte virreinal», en Jardín y Naturaleza en el reinado de Felipe II, eds. Carmen Añón y José Luis Sancho, Madrid, Sociedad Estatal para la Conmemoración de los Centenarios de Felipe II y Carlos V, I998, pp.I39-I53.

Hernando Sánchez, Carlos José, «La cultura de la villa entre Nápoles y España: los jardines de los Toledo en el siglo XVI», en Dimore signorili a napoli. Palazzo Zevallos Stigliano e il mecenatismo aristocratico dal XVI al XX secolo, ed. AA. VV., Napoli, Intesa San Paolo, 20I3, pp. II-48.

Marías, Fernando, Pinturas de historia, imágenes políticas. Repensando el Salón de Reinos, Madrid, Real Academia de la Historia, 2012.

Martins, Heitor, Manuel de Galhegos. Um poeta entre a Monarquia Dual e a Restauraçao, Anadia, 1964 .

Morán Turina, Miguel \& Fernando Checa Cremades, El coleccionismo en España. De la cámara de maravillas a la galería de pinturas, Madrid, Cátedra, 1985 .

Morán Turina, Miguel \& Isabel Sánchez Quevedo, Velázquez. Catálogo completo, Madrid, Akal, I999.

Orozco Díaz, Emilio, «Ruinas y jardines. Su significación y valor en la temática del Barroco», Temas del Barroco. De poesía y pintura, Granada, Universidad de Granada, I947.

- Paisaje y sentimiento de la naturaleza en la poesía española, Málaga, Universidad de Málaga, 2010 (2 $2^{\text {a }}$ edición).

Pommier, Edouard, «Pouvoir du portrait et portrait du pouvoir», La beauté et le paysage dans l'Italie de la Renaissance, París, Les Belles Lettres, 2013, pp. 6I-69.

Ponce Cárdenas, Jesús, Écfrasis: visión y escritura, Madrid, Fragua, 2014.

-. «Cebado los ojos de pintura: epigrama y retrato en el ciclo ayamontino», Góngora y el epigrama. Estudios sobre las décimas, Madrid / Frankfurt, Iberoamericana / Vervuert, 2013, pp. I43-I66.

Ponce Cárdenas, Jesús \& Ángel Rivas Albaladejo, El jardín del conde de Monterrey: Arte, Naturaleza y Panegírico, Salamanca, Delirio, 2018.

Portmann, Maria, «La Madeleine pénitente», L’image du corps dans l'art espagnol aux XVI e et XVII e siècles, Berna, Peter Lang, 20I4, pp. IO4-I23. 
Portús Pérez, Javier (coord.), Fábulas de Velázquez, Madrid, Museo del Prado, 2007.

-. El concepto de Pintura Española. Historia de un problema, Madrid, Verbum, $2 \mathrm{OI} 2$.

Sánchez Jiménez, Antonio, El pincel y el Fénix: pintura y literatura en la obra de Lope de Vega Carpio, Madrid / Frankfurt, Iberoamericana / Vervuert, 20II.

Santos, Fray Francisco de los, Descripción del Real Monasterio de San Lorenzo el Real del Escorial, única maravilla del mundo, fábrica del prudentísimo rey Filipo Segundo, coronada por el católico rey Filipo IV el Grande, con la majestuosa obra del Pantheón y translación de los cuerpo reales, reedificada por nuestro rey señor Carlos II después del incendio y nuevamente exornada con las excelentes pinturas de Lucas Jordán, Madrid, Juan García Infanzón, I698.

Schaub, Jean-Frédéric, Le Portugal au temps du comte-duc d'Olivares, Madrid, Casa de Velázquez, 200I.

Vega, Lope de, Obras poéticas, Barcelona, Planeta, 1989. 